\title{
ARGUMENTS FOR THE DEFINITION OF THE ICT SKILLS FOR PROSPECTIVE TEACHERS: UNIVERSITY STUDENT PERCEPTION ABOUT THE ROLE OF TEACHERS OF MATHEMATICS IN SECONDARY
}

\author{
Argumentos para la definición de competencias TICS \\ para los futuros docentes: percepción del estudiante \\ universitario sobre el papel del docente de Matemática \\ en Secundaria
}

Yuri Morales López ${ }^{1}$

\begin{abstract}
In this paper we analyze the main factors (or indicators) that may be present in the use of technology resources, specifically the use of Personal Computer (PC) and, thus, try to infer about possible ways to take advantage of this resource. The main objective of this research was to determine the perception of university students about the role of secondary mathematics teacher, specifically from the technological perspective. For this purpose, we administered a survey to collect information of 264 students in a course of Introductory Mathematics MAX - 084, in the first half of 2010 at the Universidad Nacional in Costa Rica. Principally, regarding how the mathematics teacher influenced the development of technological skills, useful for further training at the University.
\end{abstract}

Keywords: Technological competencies. Teaching. Mathematics education. Teacher training.

Resumen: En este artículo se analizan los principales factores (o indicadores) que pueden estar presentes en el uso de recursos tecnológicos, específicamente el uso de la computadora personal (PC) y de esta manera, tratar de inferir sobre posibles rutas para el aprovechamiento de este recurso. El objetivo de esta investigación fue el determinar la percepción del estudiante universitario respecto al papel del profesor de matemática en Secundaria, específicamente sobre la componente tecnológica. Para esto, se administró una encuesta a 264 estudiantes del curso de Matemática Introductoria MAX-084 en el primer semestre del 2010 en la Universidad Nacional de Costa Rica. Se pretendió conocer la forma en que pudo influir el docente de Matemática, en el desarrollo de competencias tecnológicas útiles para su formación posterior en la Universidad.

Palabras clave: Competencias tecnológicas. Enseñanza. Educación Matemática. Formación de docentes.

\footnotetext{
${ }^{1}$ Graduated in Master in Technology and Computer Education. Teacher in Mathematics Department, Universidad Nacional (UNA). Heredia, Heredia, Costa Rica. <ymorales@una.ac.cr>;

<yurimoralesl@yahoo.com>
}

Escuela de Matemática, UNA

Apt. 86-3000

Costa Rica 


\section{Introduction}

The society gradually extends and redefines the requirements demanded by its members; currently, the use of technology is a necessity tool in many areas. The dynamics of our society demand on the people who is already integrated into various productive sectors, but that requires new skills and qualities developed from persons wishing to occupy the new positions that the society itself created.

Consequently, the education expresses as one of its main principles, being in change to negotiate and to define how that will solve the need for trained professionals, and at the same time, to develop individuals with critical and creative, responsible and with the strength to change their environment, seeking the benefit of their community, respecting and caring for the Earth. This task, though difficult, is one of the main responsibilities of everyone involved in educational processes. Obviously, this responsibility must be resolved at all stages, during teaching preparation.

In higher education, such a task is more evident, as it is generally the place where a large group of people get professionalized. These professionals will attend the main demands in specialized tasks, and for this reason, they must possess suitable competencies for their future professional development.

Thus, the University should build tools to identify what are the needs of our society and to define the routes to achieve these objectives.

A problem present in this issue is that, as noted by San Martin, "the education has been isolated from the professions themselves" (SAN MARTÍN, 2009, p. 3). The practical task in the profession has been left completely sideways and has overestimated the knowledge of the contents. Furthermore, valid knowledge is generated in the academy, although this is not entirely tied to professional practice. We do not claim that the skills outweigh the importance of knowledge, but we want to establish a starting point in which the abilities and skills are also part of initial training.

Mathematics education is not an exemption from this problem. In particular, this discipline has specific factors that force it to intervene and undertake commitments in the training of teachers. For this reason, we need to know what the role of teachers is and what is expected from them. Obviously, high school students, prospective teachers, graduate teachers, employers, and society at large are a valuable source of information on this performance and how teachers have met the expectations of them.

It has been considered in this paper that a source of information relevant to the role of teachers in secondary classroom is the student who has been involved into the higher education system. It is facing the system that requires skills and abilities that Mathematics teacher had to help to stimulate.

It is clear that for the university student, the teacher has an important role in the preparation of secondary mathematics, but how good was this work? So, that the student feels comfortable in the new education environment? In particular, is the school teacher used technological tools that could foster creativity, research and problem solving? From the students' responses to these questions might be fundamental to know their reality and also to justify needed changes in educational tasks; mainly, these regarding preparing new professionals. 
Arguments for the definition of the ICT...

Therefore, this paper analyzes the main factors (or indicators) that may be present in the use of technology resources, specifically the use of PC and thus, trying to infer on possible avenues for the use of this resource.

The main objective of this research is: to determine the perception of university students regarding the role of mathematics teacher in secondary schools, specifically from the technological perspective.

We administered a survey to collect information of 264 students in Introductory Mathematics Course MAX - 084, in the first half of 2010 at the Universidad Nacional in Costa Rica (UNA), and to know how the mathematics teacher could influence the stimulation of technological skills, useful for further training in the University.

The following section outlines some key elements related to these problems and the theory that is collected from national and international literature.

\section{Theoretical framework}

In the following sections, we analyze, from the international level, the effective incorporation of technology resources and some indicators on the current role of this integration and technological skills and competencies related to training in Mathematics.

\section{Policies for the Integration of Information and Communication Technology (ICT): the INTEGRA project initiative and the proposal of UNESCO}

One of the needs of the region is to create projects that impact not only the work in the classroom, but these projects have relevance to the policies of educational institutions. Also, if we consider that several institutions already possess technological resources, from investment in the country, then, rather than a mass purchase of equipment, the schools require appropriate strategies for the use of this technology.

However, such policies cannot be separated from the knowledge of the context in which these will be applied. In this way, it should know the arguments related to the nature of knowledge, which is expected to build it and also, if these policies encourage the development of the current school curriculum.

Taking this as a premise, this paper discusses two proposals on the shaping of these policies. It should be clarified that the proposals are not intended to create a manual or guidelines, but the comparison and analysis of these proposals can display the items, in our view, that should be inherent to any implementation plan or improvement of conditions for proper use of ICT.

The first proposal is part of the INTEGRA Project, sponsored by the European Union (EU), aimed to improve the capacity of institutions for the use of ICT in Latin America. This project established five main areas:

a) Management and planning.

b) ICT and curriculum.

c) Professional development.

d) The culture of ICT in the school.

e) Resources and ICT infrastructure. 
Morales, Y.

On the one hand, among the key features of the policies developed by the INTEGRA Project, there is a direct support to participants from the institutions that are integrated into this process. Project managers help participant teachers. It includes training of principals of schools. Moreover, the strategy is that the school makes an initial proposal with the assistance of project staff on the use of technology resources and how the school evolves over time.

Along the main threads mentioned above, this project proposes a series of tasks. With respect to ICT and curriculum development, the Project points out that the incorporation of technologies must be the door to a culture of educational innovation. It is understood as a useful tool for academic work and a tool for building knowledge.

On the other hand, the management and development of ICT are based primarily on teachers as the main actors in the implementation of technology as a teaching tool, willing to be trained and willing to participate in work. But it also adds management from the educational administration, where the director takes his/her leadership role which promotes the creation of proposals.

Among the main difficulties encountered regarding the role of initial teacher training, the INTEGRA project exposes that the education sector has not created a culture about the use of technology and this causes that teachers graduated without preparation to implement technology into their practice. In many cases, universities have failed to incorporate technology as a tool for knowledge construction; there is no articulation among the various authorities called to support those processes; there is a misunderstanding on the use of technology as a goal, and, there it is difficult for a teacher to contextualize accordingly the use of these resources (PROYECTO INTEGRA, 2007)

Another proposal that offers a lot of inputs for relevant policies to incorporate technology into classrooms is presented by United Nations Educational, Scientific and Cultural Organization (UNESCO): ICT Competency Standards for Teachers (ICT-CST) (2008), whose aims are to encourage educational reform and sustainable development. This proposal has the strong influence of previous educational programs such as World Declaration on Education for All (1990), United Nations Literacy Decade Program (2003-2012) and the Millennium Development Goals of United Nations Development Programme (2000).

For the definition of such policies, the ICT-CST Programme proposes three main components or visions: Knowing the basics of ICT (technology literacy), Deepening and Knowledge generation. The same program points out that teacher education is the core of any reform or policy of incorporating technologies but notes that "teacher professional development has an impact only if it is focused on specific changes in teacher classroom behaviors and particularly if the professional development is on-going and aligned with other changes in the educational system" (UNITED UNITED NATIONS EDUCATIONAL, SCIENTIFIC AND CULTURAL ORGANIZATION, 2008, p. 9).

As seeing above, the ICT-CST Programme and the INTEGRA Project have several points of convergence with respect to the areas of these new policies (see Table 1). It is important that programs, which seek the appropriate use of ICT, assess the incorporation of some of these areas. This line reveals core points necessary to incorporate in educational policy. 
Arguments for the definition of the ICT...

Table 1. Convergence between the proposals and the main policies for the integration of technology in educational processes.

\begin{tabular}{ll}
\hline \multicolumn{1}{c}{ ICS-CST (Unesco, 2008) } & \multicolumn{1}{c}{ INTEGRA project (2007) } \\
\hline . Pedagogy & . Management and planning \\
. Practice and training of teachers & . ICT and curriculum \\
. Curriculum and assessment & . Professional development \\
. Organization and administration of the school & . The cultur of ICT in the school \\
. Use of ICT & . Resources and ICT infrastructure \\
\hline
\end{tabular}

Source: Author's own.

\section{ICT and Education, some indicators}

As we mentioned in the preamble to this paper, a fundamental part of how ICT can be incorporated into the curriculum is to know the context in which future students of these careers have been educated, and how they incorporate technology into their lives. This section outlines some indicators and relevant topics.

\section{Demand for resources and access to ICT}

The society believes that education is an engine of social mobility. In this sense, many families are concerned about purchasing computers to improve access to information. Cuevas Cordero and Alvarez Vargas (2009) suggest that families may be trying to meet the technological demands that young people require, both in knowledge and communication. In addition, families may consider these computers as learning tools, and "the families support the use of ICT in proportion to their economic means" (CUEVAS CORDERO; ALVAREZ VARGAS, 2009 , p. 62, author's translation).

Studies such as Cuevas Cordero and Alvarez Vargas (2009) show how young people use the computer. Primarily, this is used as a means to access the Internet and second option is to play. But when it comes to education, the authors note that young people do not learn more technology because they do not have money to access this resource, and although they has a PC, they do not know how to get more profit.

Although the educational material on the Internet may have some educational value, it is not until teachers take "ownership" of educational materials or software, when, in fact, may find a true sense of the use of these resources. Another problem is that "for subjects such as Science and Social Studies, access to material or preparation of this using ICT is relatively easy, but for subjects like Spanish and especially Mathematics, need special designs that are not necessarily available to most teachers” (CUEVAS; ALVAREZ; RAVASIO, 2009, p. 50, author's translation). But, we agree with Cattai and Penteado (2009), who adds that "the use of ICT opens a wide range of possibilities in the process of project implementation in schools. Besides being useful as sources of information, serve as supports for communication and publication of the work done by students" (CATTAI; PENTEADO, 2009, p. 108, author's translation). 


\section{Technological competencies in Mathematics Education}

Career training is an important issue within the higher education system. At this time, international programs such as PISA or the Tuning Project have provided a wealth of information on the future role of the citizen and their work. In both projects, the practical work seems to be a fundamental factor in professional training and competencies-based model seems to be a good option (although not perfect) to develop certain skills.

The aim of this paper is not to develop an analysis of these projects nor to discuss about the different approaches related. It is necessary to clarify what is meant in this work for competencies. According to the Tuning project, the concept of competencies can be interpreted as "a combination of attributes with regard to knowing and understanding (theoretical knowledge of an academic field); savoir-faire (practical and operative application based on knowledge); and savoir-être (values as an integral part of the way of seeing others and of living in a context)" (BENEITONE et al., 2007, p. 25).

Of course, not just how to do a specific task is related to the concept of competencies. This concept is also related to knowledge and the way in which resources are used. It refers to training and skills. Also it raises the issue whether or not the student will understand and assimilate the usefulness of such competencies. "The approach of learning, from competencies-based model, fighting against dead knowledge and against the fragmentation of knowledge in subjects" (FEITO ALONSO, 2008, p. 24, author's translation).

These competencies will be the result of the confrontation between the theory and practice in educational environments agreed between the teacher, the students and the support from prospective employers. Such environments should involve situations where creativity and problem solving competencies are essential. Apparently the next question is how to implement and to integrate theory and practice?

In the context of higher education, Yániz (2005, p. 29, author's translation), said that

From the perspective of university education, stresses the idea that to successfully perform a particular function, people need knowledge, attitudes and skills. This challenges some widespread beliefs at this level, for example, that a knowledge-based training is enough for people to achieve good practice in a complex field, which attitudes are improper to university education, and competencies are more related to personal skills, rather than formal learning.

Another factor that deserves attention is that for change like that to take place it will take time and work to modify the plans of the teacher training courses, but it can be anticipated that some university faculty will neglect on the changes and ways or strategies to achieve the goals proposed in such plans.

This raises many questions concerning the role of teacher at university classroom and the strategies that these teachers must understand. The implications of a project that will change their career to base it on competencies. It is even necessary to ask if university teachers should acquire these competencies to guide students. If this is correct, will there be a training 
program to support such a task? Or is it necessary to admit that, ultimately, the teacher will be solely responsible for adapting strategies, methodologies and objectives?

Regarding the use of the PC and the use of these resources, it is necessary to define if it is expected that, for example, the school teachers learn to manage computerized educational materials. If so, then what issues and strategies will arise within the Mathematics Education curricula to encompass the selection and use of these materials?

This problem is not so simple, and then the teacher should have a relevant training in the area of mathematics and its pedagogy, but how much is preparing to test a computerized educational material; are the concepts such as access, relevance and interactivity, fully clear and understood? Are these concepts part of a technical component close to university teaching and the prospective secondary teacher? If it deemed necessary to integrate these issues, is there appropriate human resource to advice on these topics? Pursuing these questions exceed the expectations of this paper, but future researches should address them.

Finally, regarding the proposals on this subject, for example, Silva, Gros, Garrido and Rodríguez (2006, p. 7) offer another proposal in six dimensions. According these authors, these dimensions help to define the competencies in the training of trainers:

1. The first (basic) in connection with the handling and proper use of hardware and operating software.

2. Designing Learning Environments, understood as the ability to organize teaching and learning environments with the use of technology. 3. Linking ICT with the curriculum, where the teacher gives the significance of performing a learning process, from the needs of the curriculum (standard curriculum) to enable a learning context.

4. Assessment of resources and learning, focusing on technical competencies and critically evaluate the impact of use of certain resources and organization of learning environments.

5. Professional development, understood as those abilities and skills that allow teachers to continue learning processes and ICT.

6. Ethics and values oriented legal elements and ethical use of resources.

On the other hand, there are proposals to the definition of areas or dimensions for the training of teachers of Mathematics. For instance, Morales (2010) outlines that the prospective teacher of mathematics must have certain basic skills. These were grouped under seven categories: basic technological competencies, diversity-related technological competencies and computer ethics, technological competencies related to the administration of the educational process, technological competencies related to pedagogical administration of the educational process, methodologies related technological competencies in the educational process, technological competencies related to virtual communities and Blended Learning, and competencies related to specific software.

Such proposals may provide a general starting point for discussion from the academic as a starting point to build their own project in institutions or universities. Eventually, these ideas will be part of initiatives that may provide a better perspective on this issue. 
The next paragraphs, will described the methodology followed in this research, analysis and main conclusions.

\section{The methodology}

This paper has been developed under the premise that education, as a process, is complex and difficult to describe. It is not intended that as a result of this research, the reader will infer about the entire population, because the type of research was descriptive, under a quantitative-qualitative approach.

Consequently, the research is based on the description of the indicators (parameters or factors) related to the research problem, to know what are the elements related to the issue. The strategy is based on a critical analysis of such descriptors and crossing of variables set. Furthermore, this work focused on the use of the PC, noting that there are other relevant resources related to the incorporation of ICT in the classroom.

The study was conducted during the first half of 2010 at Universidad Nacional (National University) of Costa Rica. We selected nine groups of Introductory Mathematics course (precalculus MAX-084). The sample included 264 students (51.5\% women) whose average age was between 19 and 20 years.

The sample was selected by convenience in the sense that we selected the students who enrolled the Introductory Mathematics course. This course hosts many students who enter various careers and fields of knowledge. This allows students were not grouped by affinity (as the case of introductory courses to specific careers) or school of origin, while about 7 in 10 students come from an urban area.

\section{Instrument to collect data and indicators}

The survey's main objective was to collect information regarding the use of the computer during high school, specifically in mathematics classes, and the way in which the student received such implementation. Accordingly, the instrument consisted of five parts: personal information, information about computer use, information about knowledge (mathematical and pedagogical), information about the use of the PC in the mathematics classes in high school and information about their teachers and the skills to use ICT. In the survey, we used closed questions and we designed some Likert scales to collect perception in various indicators.

\section{Design of parameters}

1. Indicator of knowledge in the PC: This indicator is constructed from information relating to computer ownership, management, where and when they learned to use the PC, use of basic software and participation in virtual communities.

2. Indicator regarding the use of the PC in mathematics education: this is defined with respect to the resources possessed by the institution, how the teacher used the PC, the reasons why teacher used the PC or not. 
Arguments for the definition of the ICT...

3. Indicator on the role of teachers in mathematics, mainly from the use of the PC: was established from the way they used the PC, the technological competencies and competencies that the student polled considers necessary.

4. Given the fact that this research took into an account ranges for which, the tests are non-parametric, it was necessary to use a correlation coefficient and Spearman's Rho. Moreover, according to Weimer (2003) this correlation is ideal, because it is not possible to ensure that data obtained in this study met the normality assumption. Also, the main objective to use this correlation was to find a level of intensity, to explain possible relationships of indicators in the instrument. Below, we detailed the analysis of relevant parameters.

\section{Analysis}

In this section, we analyze the main evidence detected in relation to the factors defined above. It will describe the main statistics of the sample and it makes a crossing of variables to explore possible relationships between them.

Regarding the factor of basic knowledge of the PC, it was found that the majority of students from the sample have a computer at home (91.9\%). This may represent a fundamental factor, then, in most cases, access may not be an obstacle. This is consistent because many of them have expressed at least a basic knowledge on its use $(97.3 \%)$.

This is steady because, according to the data, $54.7 \%$ of people learned to use the computer before going to Secondary and $93.8 \%$ before entering the university. This is a good indicator for entering a career, that most students have basic competencies. These competencies appear to be more stimulated at home $(40.2 \%)$ than in primary and secondary together $(39.4 \%)$.

Regarding the software, more than, 50\% said they could use almost completely and fully software such as Word, Excel, PowerPoint, Windows Explorer and Paint. Protrude the use of chats, in which, $76.3 \%$ said knowing how to use almost or completely.

This indicator shows that students who were interviewed knew some of the basic resources, and students know that these resources are also available for teachers. Most students already knew the basic use of the PC, which may have allowed them to use this knowledge in school classes, i.e., ignorance about the use of the PC, could not be an issue to discriminate the work with the PC in the classroom.

The indicator on the use of PC in mathematics education, 8 of 10 students felt that their mathematics teachers did not use the PC in "the right way" and they did not use all the resources they had available. Of these, $63.5 \%$ felt that the teacher did so, for lack of interest or ignorance, while the other students felt that the main reason was poor infrastructure or resources, as shown in Figure 1.

In addition, if we select students who felt that their teachers of mathematics at high school did use the PC properly, 75\% said that their main reason was the interest of student learning. Regarding the use that teachers gave to the PC, highlights:

a) $81.8 \%$ said they agree, strongly agree or completely agree, that the computer was used to learn mathematics. 
Morales, Y.

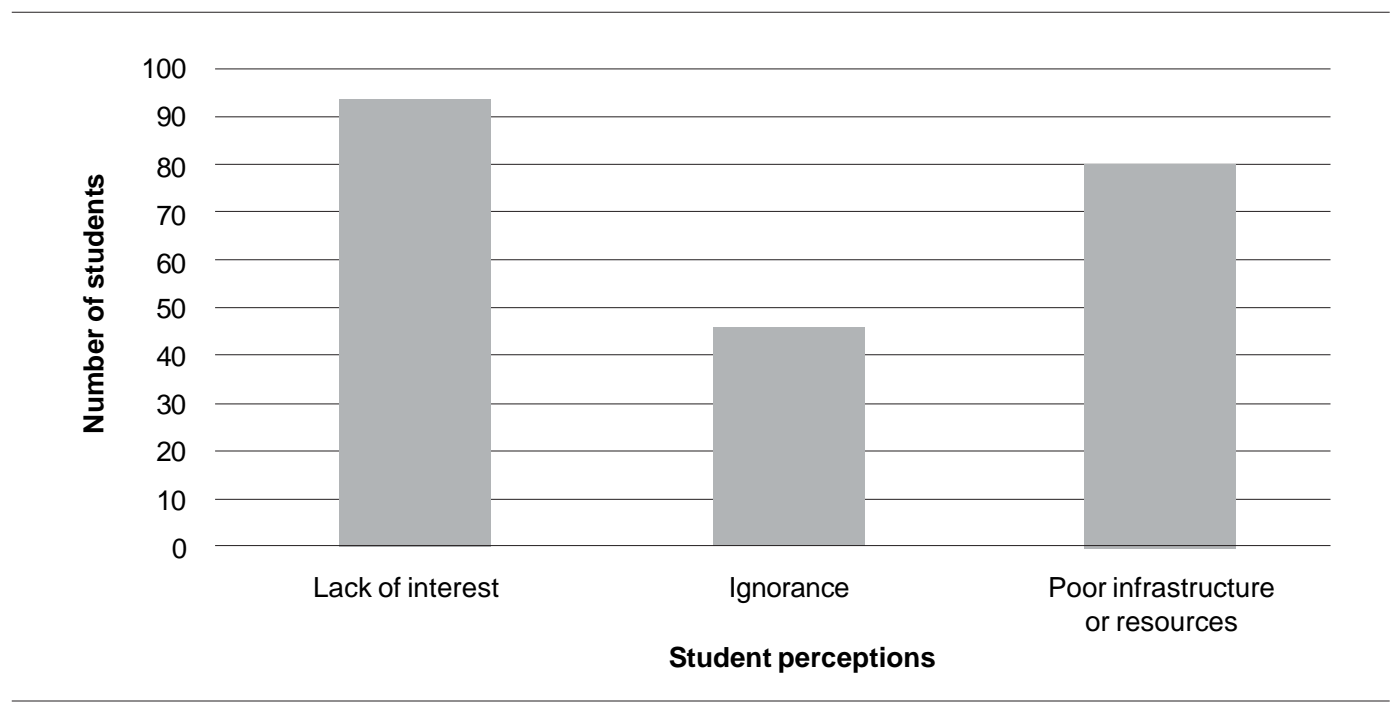

Figure 1. Student perceptions about the main reason that their teachers do not incorporate the $P C$ in mathematics classes, UNA, 2010.

b) $63.6 \%$ said they agree, strongly agree or completely agree that computer was used to expose the issues.

c) $59.4 \%$ said they disagree or strongly disagree that the PC is used to solve real life problems.

d) On average, students said they agreed or strongly agreed that to use of computer helped to motivate them (Std Deviation $=1.321$ )

From this data we can draw several outcomes. First, the student found that the majority of mathematics teachers do not know how to use the PC as a resource for teaching or they are not motivated. Second, if we select the teachers who did use the PC, most students agree that the teacher did have interest in teaching, but without applying methodologies related to the resolution of problems or contextualizing knowledge.

About the last indicator, participants were asked if they thought it was important to use the tool in high school, and if they perceived that this might have simplified the learning of mathematics (independent, that they have been trained with support from the PC or not). $45.6 \%$ thought that this was not necessarily true.

Based on the experience that students have in secondary and university, there is an order (on a scale of importance, with 1 being the most important and 6 the least important) on the issues relevant to the formation of mathematics teachers (see Figure 2).

As we mentioned in the methodology section, we analyzed the possible relationship between the variables of interest. The Rho of Spearman showed that people who mentioned that the most important competence for teachers of mathematics is related to design and implement creative, too, felt that the ethical use of resources, the basic manipulation of the PC, and the management student records, are the issues less relevant. In the same way: the use of the Internet, virtual communities and chat rooms (see Table 2). 
Arguments for the definition of the ICT...

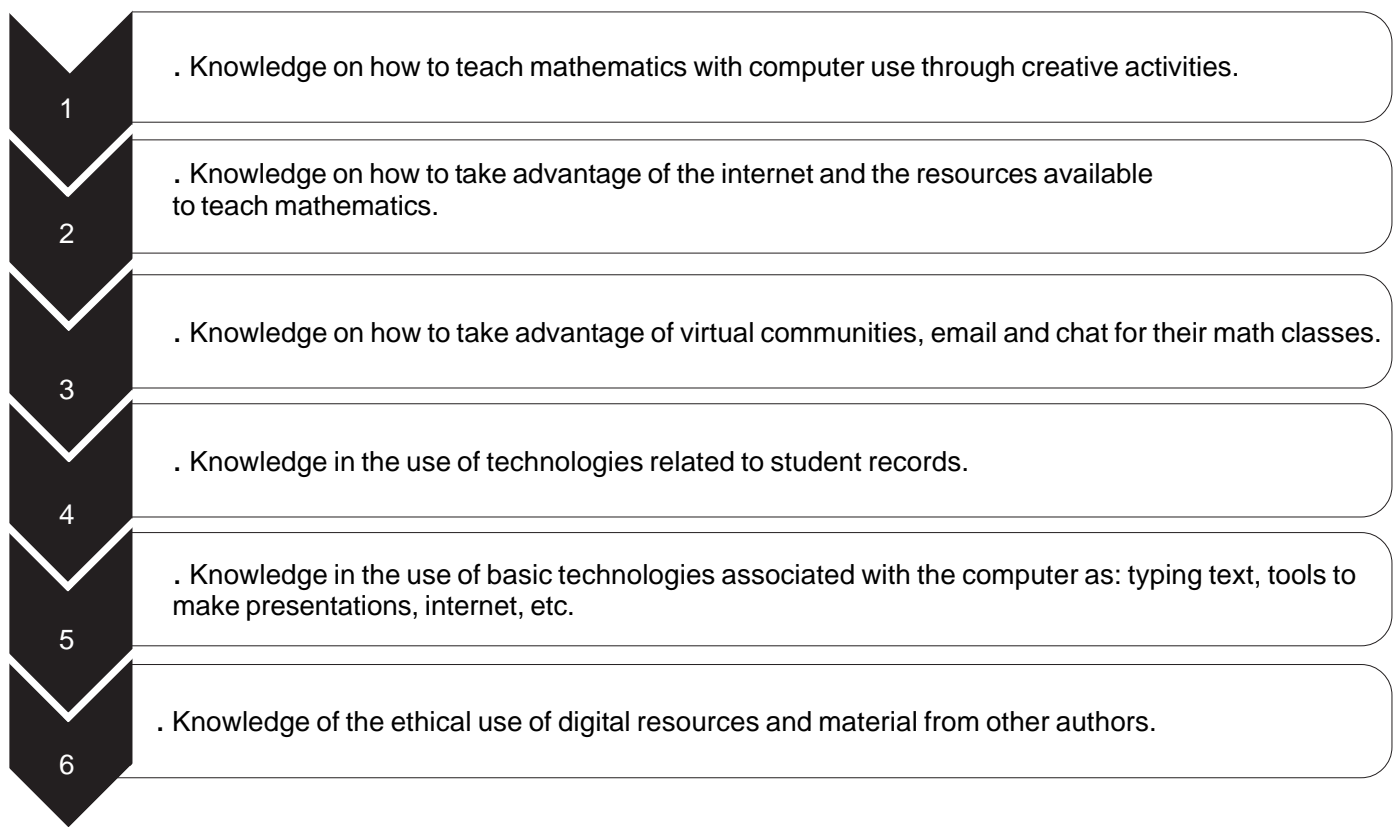

Figure 2. Perception of students in the university regarding the most important issues in the training of secondary teachers of Mathematics, UNA, 2010.

Table 2. Correlation of Spearman for the student's perception of the most important skills for teachers of Mathematics, UNA, 2010

\section{Knowledge in the use of basic technologies associated with the computer as: typing text, tools to make presentations, Internet etc.}

\section{Knowledge of the ethical use of digital resources and material from other authors}

Knowledge in the use of technologies related to student records

Knowledge on how to teach $-.355^{* *}$ $-.198^{\star \star}$ $-.389^{* *}$ mathematics with computer use through creative activities.

Knowledge on how to take advantage of the Internet and the resources available to teach mathematics.

Knowledge on how to take advantage of virtual communities, email and chat for their mathematics classes.

\footnotetext{
${ }^{*}$ : Correlation is significant at the 0.01 level (2-tailed). Source: Author's own.
} 


\section{Final discussion}

One way or another, in many training programs there is exists issues related to the management of technological resources, primarily using the PC. Although these issues have some organization and moreover, there are introductory courses to the use of resources in a basic way, accordingly these programs have omitted relevant aspects about the method that these resources are used during the career.

This situation goes beyond the fact that the student knows the use of software in a course or another, the substance appears in the moment that we consider these resources as tools for learning. e.g., how the teachers learn? And, what will be their role when they arrive to the classroom?

In these programs, to give meaning to technology will depend in large measure, if the courses are directed to the use of these applications. That is, teachers of secondary not only will need that the curriculum gives them expertise in the handling of resources, but at the same time, Mathematics and Pedagogy courses can incorporate these technologies in its work. This knowledge in the courses is essential; therefore, it allows the teachers to incorporate specific and integrated activities with a clear objective. If we confront the expected competencies to the specific activities, it will be possible to determine or assess the degree of compliance with these efforts.

Thus, the incorporation of technology may not only be a framework of issues, but must be translated into activities that match the competencies that define each career. Unfortunately, the reality is that many careers have no plans or goals from one level to another. In addition, these careers separate and isolate the mathematics courses and educational courses.

In summary, there is a need to conform working groups by level to meet some arguments in this paper. These groups must to evaluate relevant activities at the assigned level. This is to meet with the integration between that level, the previous and next one.

Finally, it is necessary to clarify that we cannot establish a proposal suitable for all careers, because much will depend on the goals and profiles of each career. We intended with this research, to provide an input for possible changes in the programs of training teachers of Mathematics at the national and international scope.

\section{References}

BENEITONE, P. et al. (Eds.). Reflections on and outlook for higher education in Latin America. Final report: Tuning Latin America Project 2004-2007. Bilbao: Publicaciones de la Universidad de Deusto, 2007.

CATTAI, M. D. S.; PENTEADO, M. G. A formação do professor de matemática e o trabalho com projetos na Escola. Ciência \& Educação, Bauru, v. 15, n. 1, p. 105-120, 2009.

CUEVAS, F.; ALVAREZ, V.; RAVASIO, P. Brecha digital en la educación secundaria: el caso de los profesores costarricenses. San José: Universidad de Costa Rica, Programa Sociedad de la Información y el Conocimiento, 2009. Available from: <http:// www.prosic.ucr.ac.cr/images/pdf/Profesores.pdf>. Access in: 17 Oct. 2009. 
Arguments for the definition of the ICT...

CUEVAS CORDERO, F.; ALVAREZ VARGAS, V. Brecha digital en la educación secundaria: el caso de los estudiantes costarricenses. San José: Universidad de Costa Rica, Programa Sociedad de la Información y el Conocimiento, 2009. Available from: <http:// www.prosic.ucr.ac.cr/images/pdf/Estudiantes.pdf>. Access in: 17 Oct. 2009.

FEITO ALONSO, R. Competencias educativas: hacia un aprendizaje genuino. En Portada, Madrid, v. 2, n. 66, p. 24-36, 2008.

MORALES, Y. En búsqueda de las competencias tecnológicas en la formación de formadores en matemáticas. Cuadernos de Investigación y Formación en Educación Matemática, San José, v. 5, n. 6, p. 63-80, 2010.

PROYECTO INTEGRA. Políticas públicas para la inclusión de las TIC en los sistemas educativos de América Latina: resultados del Proyecto @lis/INTEGRA. [S. 1.]: EuropeAid, 2007. Available from: <http://www.oei.es/tic/INTEGRA_Politicas.pdf>. Access in: 3 Feb. 2009.

SAN MARTÍN, V. La formación en competencias: el desafío de la educación superior en Iberoamérica. Available from: <http://www.rieoei.org/deloslectores/280SanMartin.PDF>. Access in: 25 Oct. 2009.

SILVA, J. et al. Estándares en tecnologías de la información y la comunicación para la formación inicial docente: situación actual y el caso chileno. Revista Iberoamericana de Educación; v.38, n. 3, p. 1-16, 2006. Available from: <www.rieoei.org/deloslectores/ 1391Silva.pdf>. Access in: 3 Sept. 2008.

UNITED NATIONS DEVELOPMENT PROGRAMME. Millenium Development Goals. Available from: <http://www.undp.org/mdg/>. Access in: 23 May 2010.

UNITED NATIONS EDUCATIONAL, SCIENTIFIC AND CULTURAL ORGANIZATION. ICT competency standards for teachers: policy framework. Paris: Unesco, 2008.

World Declaration on Education for All. Paris: Unesco, 1990.

WEIMER, R. Estadística. México: Compañía Editorial Continental, 2003.

YÁNIZ, C. Las competencias en el currículo universitario: implicaciones para la formación del profesorado. Revista de la Red Estatal de Docencia Universitaria, Bilbao, v. 4, n. 2, p. 31-39, 2005.

Artigo recebido em 06/10/2010. Aceito em 28/03/2011. 